\title{
Isolation of Apigenin by solute-solvent extraction from Symphotrichum novea anglea
}

\author{
Huma Aslam Bhatti* and Rubina Noor \\ H.E.J. Research Institute of Chemistry, International Center for Chemical and Biological Sciences, University of Karachi, Karachi, Pakistan
}

\begin{abstract}
Apigenin is polyphenolic compound that belong to the class of flavonoid and considered as highly antioxidant. In the current research Symphyotrichum novae-angliae is identified as rich source of apigenin. Crude ethyl acetate extract of the flower of Symphyotrichum novae-angliae washed with ethyl acetate. The ethyl acetate insoluble part was apigenin. The isolated compound was identified by EIMS and ${ }^{1} \mathrm{H}-\mathrm{NMR}$ techniques.
\end{abstract}

\section{Introduction}

Flavonoids are polyphenolic compounds having diphenylpropanes $\left(\mathrm{C}_{6} \mathrm{C}_{3} \mathrm{C}_{6}\right)$ skeleton in their structure. Polyphenols are the compounds that contains more than one hydroxyl group in their structure. Flavonoids are classified on the basis of $\mathrm{C}_{3}$ ring as flavones, flavanols, isoflavones, flavonones, flavonol, anthocyanin and chalcone etc. [1]. Flavones belong to the benzopyran class consisting an important group of oxygen heterocycles, present in many fruits and vegetables (Figure 1) $[2]$.

Flavonoids having large variety of pharmacological and biochemical effects including anti-inflammation, antioxidant, antiplatelet, anti-allergic and anti-thrombotic [3-6]. In which flavones exhibit a great diversity in their biological activities because of their unique ability to modulate various enzyme systems [7]. Flavones are active natural product against metabolic and infectious diseases and they also possess anti-estrogenic, anti-inflammatory, anti-microbial [2], as well as antioxidant, anti-allergic [3], Anti-tumor and cytotoxic activity [8].

Symphyotrichum novae-angliae is one of the natural products that contains flavones. Symphyotrichum novae-angliae belongs to family Asteraceae, are the rich source of apigenin. Apigenin is considered as highly antioxidant compound which exhibit many biological

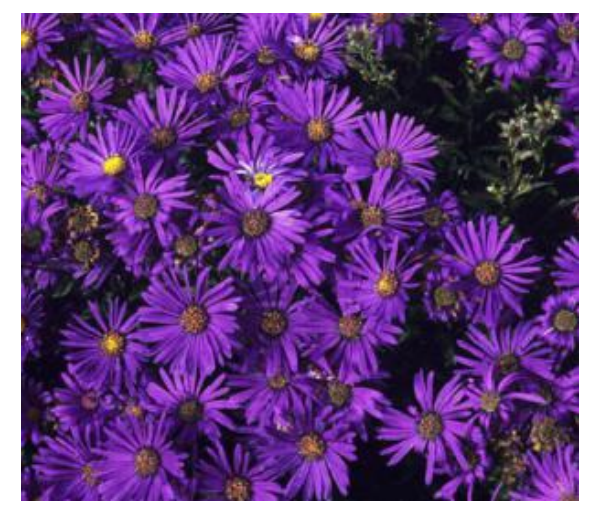

Figure 1. Symphyotrichum novae-angliae activities such as free radical scavenger, anti-inflammatory, anticancer, [9], antiviral, antitumor, and antibacterial activities, they are cytoprotective and neuroprotective agents [10]. Apigenin have been isolated from different sources. So far apigenin has been isolated by normal phase column chromatography [11], sephadex [12,13], HPLC [14] and so on. All the methods for the purification or isolation of compounds are expensive and time consuming. In the current research we have found new method for the isolation or purification of apigenin that was not reported yet. The current method for the purification of apigenin is crude-solvent extraction method by using solvent in small quantity and also time saving. Apigenin that was isolated from Symphyotrichum novae-angliae was obtained in large quantity and directly from extract.

\section{Experimental}

\section{General}

Solvents were purchased from sigma Aldrich. EI-MS spectrum was recorded in Brucker and its mass fragments is expressed by $\mathrm{m} / \mathrm{z}$ while the spectrum of ${ }^{1} \mathrm{HNMR}$ was recorded in (Brucker Avance, 500 $\mathrm{MHz}$, with TMS as an internal standard,) Chemical shift and coupling constant were calculated in ppm and $\mathrm{Hz}$.

\section{Plant material}

Flower of Symphyotrichum novae-angliae were collected in the month of March-2017 from the garden of H.E.J. International Center for Chemical and Biological Sciences, University of Karachi. The plant specimen was identified by Dr. Muneeba Khan and deposited in the

${ }^{\star}$ Correspondence to: Huma Aslam Bhatti, H.E.J. Research Institute of Chemistry, International Center for Chemical and Biological Sciences, University of Karachi, Karachi, Pakistan, E-mail: huma_aslam31@hotmail.com

Key words: apigenin, solute-solvent extraction, Symphyotrichum novae-angliae, ethyl acetate

Received: September 12, 2019; Accepted: October 03, 2019; Published: October 07, 2019 
herbarium, University of Karachi. A voucher specimen number is G.H. No. 94959.

\section{Method of purification}

The flowers $(80 \mathrm{~g})$ of Symphyotrichum novae-angliae (Purple in color) separated from stems and soaked in ethyl acetate for three days at room temperature. Then the ethyl acetate extract was filtered and concentrated by using rotary evaporator in order to obtained crude. The obtained crude washed with ethyl acetate to get ethyl acetate soluble and some insoluble part, here we obtained purified single compound from ethyl acetate insoluble part $(233.6 \mathrm{mg})$. The ethyl acetate insoluble part, soluble in the mixture of dichloromethane and methanol and gave single spot on TLC. Further this compound was identified by spectroscopic technique.

\section{Spectroscopic data of isolated compound}

Apigenin was isolated as yellow powder. The EI-MS spectrum showed molecular ion peak at m/z: 270.2.

${ }^{1} \mathrm{HNMR}\left(400 \mathrm{MH}_{\mathrm{Z}}, \mathrm{DMSO}-d_{6}\right): \delta 12.9(\mathrm{~s}, 1 \mathrm{H}, \mathrm{Ar}-\mathrm{OH}), 7.91(\mathrm{~d}$, $\left.J_{2^{\prime}, 3^{\prime} / 6^{\prime}, 5^{\prime}}=8.8 \mathrm{H}_{\mathrm{Z}}, 2 \mathrm{H}, \mathrm{H}-2^{\prime}, 6^{\prime}\right), 6.91\left(\mathrm{~d}, J_{3^{\prime}, 2^{\prime} / 5^{\prime}, 6^{\prime}}=8.8 \mathrm{H}_{\mathrm{Z}}, 2 \mathrm{H}, \mathrm{H}-3^{\prime}, 5^{\prime}\right)$, $6.76(\mathrm{~s}, 1 \mathrm{H}, \mathrm{H}-3), 6.47\left(\mathrm{~d}, J_{8,6}=1.6 \mathrm{H}_{\mathrm{z}}, 1 \mathrm{H}, \mathrm{H}-8\right), 6.18\left(\mathrm{~d}, J_{6,8}=2.0 \mathrm{H}_{\mathrm{z}}, 1\right.$ $\mathrm{H}, \mathrm{H}-6)$.

\section{Result and discussion}

Apigenin is polyphenolic compound and found in many plants, they possess many pharmacology activities. Their purification method is based on column chromatography and high-performance liquid chromatography. Since all the reported method are expensive and time consuming. In the current research we have reported the method for the purification of apigenin from their extract without using any column chromatographic technique. Extract from flower of Symphyotrichum novae-angliae was obtained by soaking the flower in ethyl acetate, these extracts washed with again ethyl acetate and we got apigenin in the pure form from the ethyl acetate insoluble part with high yield. Here we isolated $233.6 \mathrm{mg}$ apigenin from $80 \mathrm{~g}$ of fresh flower petals. Purified compound was characterized by EIMS and ${ }^{1} \mathrm{H}-\mathrm{NMR}$. Apigenin was obtained as a yellow powder, their molecular ion peak was observed at $\mathrm{m} / \mathrm{z} 270$ (Figure 2). ${ }^{1} \mathrm{H}-\mathrm{NMR}$ was taken in the deuterated dimethylsulfoxide, the hydroxyl proton appeared at $12.9 \mathrm{ppm}$. The proton at position $2^{\prime}$ and $6^{\prime}$ due to symmetrical structure appeared as a doublet at $7.91 \mathrm{ppm}$ and proton of $3^{\prime}$ and $5^{\prime}$ at $6.91 \mathrm{ppm}$, upfield due to neighbour electron donating (hydroxyl) group. Proton of $\mathrm{H}-3$ shown singlet at $6.76 \mathrm{ppm}$. H-8 and H-6 gave doublet signal at 6.47 and 6.18 ppm (Figure 3).
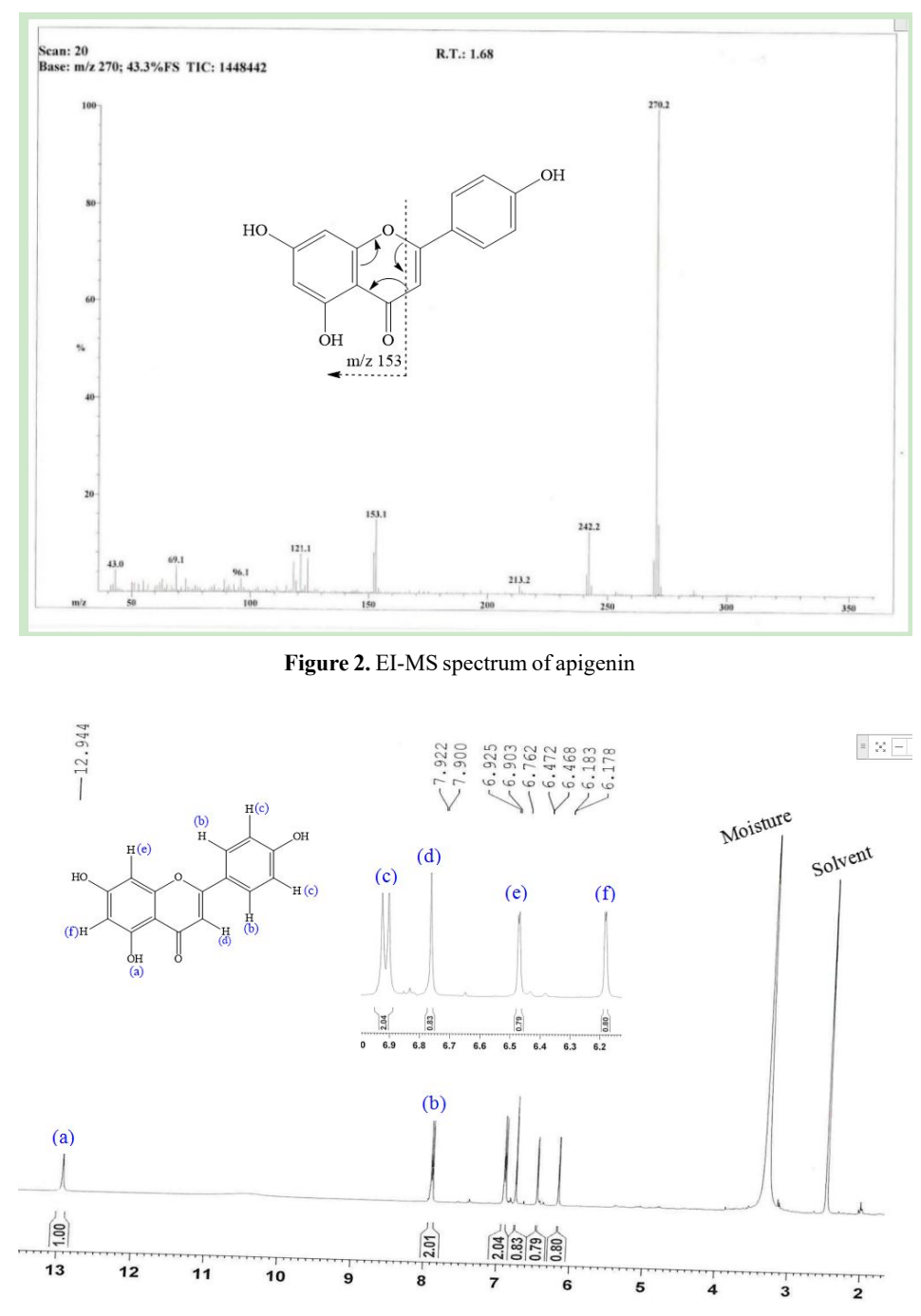

Figure 3. ${ }^{1} \mathrm{H}-\mathrm{NMR}$ spectrum of apigenin 


\section{Conclusion}

Apigenin is considered as highly antioxidant compound and belong to polyphenolic class of natural product. This compound is also commercially available but it is expensive due to their purification method. Symphyotrichum novae-angliae belong to family asteraceae, identified as rich source of apigenin. In the current research apigenin was obtained from the extract of Symphyotrichum novae-angliae by using ethyl acetate for washing of crude mixture. This method of isolation required less amount of solvent and we obtained apigenin in the large quantity. From this plant we can obtained apigenin in large amount by saving time due to this method.

\section{References}

1. Andersen OM, Markham KR (2005) Flavonoids: chemistry, biochemistry and applications. CRC press.

2. Cushnie TT, Lamb AJ (2005) Antimicrobial activity of flavonoids. International Journal of Antimicrobial Agents 26: 343-356.

3. Havsteen B (1983) Flavonoids, a class of natural products of high pharmacological potency. Biochemical Pharmacology 32: 1141-1148.

4. Gryglewski RJ, Korbut R, Robak J, Swies J (1987) On the mechanism of antithrombotic action of flavonoids. Biochemical Pharmacology 36: 317-322.
5. Middleton Jr E, Kandaswami C (1992) Effects of flavonoids on immune and inflammatory cell functions. Biochemical Pharmacology 43: 1167-1179.

6. Cook NC, Samman S (1996) Flavonoids - chemistry, metabolism, cardioprotective effects, and dietary sources. The Journal of Nutritional Biochemistry 7: 66-76.

7. Verma AK, Pratap R (2010) The biological potential of flavones. Natural Product Reports 27: 1571-1593.

8. Middleton E, Kandaswami C, Harborne J (1993) The flavonoids: advances in research since 1986. Chapman \& Hall/CRC, New York.

9. Papay ZE, Balogh E, Zariwala MG, Somavarapu S, Antal I (2015) Drug delivery approaches for apigenin.

10. Kumar S, Pandey AK1 (2013) Chemistry and biological activities of flavonoids: an overview. ScientificWorldJournal 2013: 162750. [Crossref]

11. Suntar I, Akkol EK, Keles H, Yesilada E, Sarker SD (2013) Exploration of the wound healing potential of Helichrysum graveolens (Bieb.) Sweet: Isolation of apigenin as an active component. Journal of Ethnopharmacology 149: 103-110.

12. Loizzo MR, Said A, Tundis R, Rashed K, Statti GA, et al. (2007) Inhibition of angiotensin converting enzyme (ACE) by flavonoids isolated from Ailanthus excelsa (Roxb) (Simaroubaceae). Phytotherapy Research 21: 32-36.

13. Zhang X, Liu Z, Bi X, Liu J, Li W, et al. (2013) Flavonoids and its derivatives from Callistephus chinensis flowers and their inhibitory activities against alpha-glucosidase. EXCLI Journal 12: 956.

14. Jager AK, Krydsfeldt K, Rasmussen HB (2009) Bioassay-guided isolation of apigenin with GABA-benzodiazepine activity from Tanacetum parthenium. Phytotherapy Research 23: 1642-1644.

Copyright: (C2019 Bhatti HA. This is an open-access article distributed under the terms of the Creative Commons Attribution License, which permits unrestricted use, distribution, and reproduction in any medium, provided the original author and source are credited. 